\title{
The Impact of Antithyroid Antibodies on Pregnancy Outcome following Intracytoplasmic Sperm Injection (ICSI) cycle
}

\author{
Abdel Fattah Mohamed Al Sayed AlSinety ${ }^{1}$, Asem Anwar Abdo Mousa ${ }^{1}$, Ahmed Samy Soliman Amer ${ }^{1}$, \\ Ahmed Mohamed Kamal Fata ${ }^{2}$, Hagagy AbdAlatif Ahmed Abozeid ${ }^{1}$ \\ 1Obstetrics and Gynecology Department, 2International Islamic Center of Population Studies and Researches, Faculty of Medicine, Al- \\ Azhar University \\ * Corresponding author: Hagagy AbdAlatif Ahmed Abozeid, E-Mail: hagagabdalatif@gmail.com
}

\begin{abstract}
Background: the presence of antithyroid antibodies (ATA) are frequently encountered in general population and approximately $1 / 5$ of childbearing age women are positive for the antithyroid peroxidase antibody (TPO$\mathrm{Ab}$ ) or antithyroglobulin antibody (TG-Ab). Autoimmune thyroid diseases are rather frequent in women in the childbearing age, affecting 5-20\% of them. They are characterized by the presence of antithyroglobulin and antithyroperoxidase antibodies, grouped under the definition of ATA. ATA are often detected in subjects complaining of hypo- or hyperthyroidism, but are no rarely found in patients without any sign of thyroid dysfunction.
\end{abstract}

Aim of the Work: to investigate the impact of antithyroid antibodies on pregnancy outcome in cases of one or two failure of Intracytoplasmic Sperm Injection (ICSI) cycle.

Patients and Methods: the present study is a prospective study. This study was conducted at Ahmed Oraby IVF center (private center), and was approved by the Medical Ethical Committee of Al-Azhar University. Informed consent was obtained from every patient according to Hospital Ethics Committee. Age of patients, diseases status and previous treatments were recorded. This study was done on 50 patients complaining of infertility with history of one or two failure of ICSI cycle and patients divided into two groups, in the ATA positive group, 25 women were positive for TG-Ab and/or TPO-Ab, 25 women negative for TG-Ab and/or TPO-Ab served as controls. All patients did not receive any adjuvant treatment, such as glucocorticoids, anticoagulants, or other adjuvants. Patients with other autoimmune diseases, or positive for anticardiolipin antibody, antinuclear antibody, lupus anticoagulant, or rheumatoid factor were excluded from this study.

Results: there were no significant differences in age, BMI, basal LH, FSH levels, cause of infertility and duration of infertility between two main groups. No significant differences in terms of the days of ovarian stimulation, estradiol level, total gonadotropins dose, number of oocytes retrieved, available embryos and blactocysts number neither of embryos transferred nor in rates of fertilization, implantation and clinical pregnancy between two main groups were found. The only statistically significant among the ATA positive group increase the abortion rate was found $\mathrm{p}$ value 0.02 .

Conclusion: patients with anti-TPO antibodies showed no significant differences in fertilization, implantation, pregnancy rates, live birth rates but higher risk for miscarriage following intracytoplasmatic sperm injection-ICSI and embryo transfer when compared with those negative for anti-thyroid antibodies.

Keywords: Antithyroid Antibodies, Intracytoplasmic Sperm Injection, Antithyroglobulin, Antithyroid Peroxidase Antibody

\section{INTRODUCTION}

The presence of antithyroid antibodies (ATA) are frequently encountered in general population and approximately $1 / 5$ of childbearing age women are positive for the antithyroid peroxidase antibody (TPO-Ab) or antithyroglobulin antibody (TG-Ab) (1). Autoimmune thyroid diseases are rather frequent in women in the childbearing age, affecting $5-20 \%$ of them. They are characterized by the presence of antithyroglobulin and antithyroperoxidase antibodies, grouped under the definition of antithyroid antibodies (ATA). ATA are often detected in subjects complaining of hypo- or hyperthyroidism, but are no rarely found in patients without any sign of thyroid dysfunction ${ }^{(2)}$. Some evidence suggests that ATA could exert a negative influence on the female reproductive potential.
Women with no signs of thyroid dysfunction who were ATA positive, the risk of spontaneous miscarriage increased three to five folds more than ATA negative women ${ }^{(3)}$. Some authors even reported an unexpectedly high ATA prevalence in euthyroid women with a history of three or more unsuccessful IVF cycles, and ATA-positivity was found to be associated with a low pregnancy rate in IVF. On the contrary, other studies failed to detect any difference in IVF success rate between ATA positive and ATA negative women ${ }^{(4)}$. Previous researches showed there were $10.5 \%$ of infertility women who were positive for ATA ${ }^{(5)}$. It has been shown that the TPO-Ab level was associated with the thyroid stimulating hormone (TSH) level: 1) TPO-Ab positive women had significantly increase TSH level. 2) Some women with normal TSH level were found to be positive for TPO-Ab ${ }^{(6)}$. The presence of ATA in euthyroid women may be 
related to some fertility problems such as increased abortion rate and raised incidence of infertility. In recent years, some researchers speculated that assisted conception women positive for ATA had poor outcome of in vitro fertilization, even they were euthyroid ${ }^{(7)}$. Thyroid hormone receptors have been described in human oocyte and may assist in the stimulation of granulose cell function and trophoblastic differentiation. It has been suggested that antithyroid antibodies may be responsible for decreased fertility potential by blocking these receptors. Thus, the impact of these antibodies on the outcome of IVF cycles has been investigated. Although the presence of ATA was found to be related with poor IVF outcome in some studies ${ }^{(5)}$. Miscarriage rate was not found to be higher in IVF pregnancies achieved in ATA-positive women compared with ATA-negative women ${ }^{(8)}$. The miscarriage rate and increased incidence of infertility are associated with higher ATA levels ${ }^{(9)}$. A detrimental impact was found between the presence of anti-TPO and spontaneous abortion on the contrary with those obtained by karacan. ${ }^{(10)}$ where miscarriage rates and ongoing pregnancy rates did not differ significantly between the ATApositive group and the ATA-negative group. Additionally, the study presented by Mintziori. ${ }^{(11)}$ found no evidence that increased TSH concentrations or the presence of TAI determined before IVF affect the live birth rate in euthyroid women. That study included women with TSH level of $0.5-4.5 \mathrm{IU} / \mathrm{mL}$. Increased risk of miscarriage and recurrent miscarriage in ATApositive euthyroid women having spontaneous pregnancy has been demonstrated but the exact mechanism is not well established. The presence of ATA may implicate chronic lympocytic thyroiditis which subsequently leads to inadequate response of the thyroid to the increased demand during pregnancy. Thus, detection of ATA may be beneficial to identify women at high risk for hypothyroidism and subsequent miscarriage due to thyroid dysfunction ${ }^{(12)}$. The presences of ATA are associated with an increased risk of miscarriage in subfertile women who conceived through ICSI. However, miscarriage rate was not found higher in ICSI pregnancies achieved in ATA-positive women compared with ATA-negative women ${ }^{(8)}$. It was stated that ovarian stimulation might have suppressive effect on humoral immunity by the time of embryo transfer. This might be a factor to obtain comparable pregnancy rates in ATApositive women undergoing ICSI ${ }^{(13)}$. The use of levothyroxine, acetylsalisylic acid and prednisolone as an adjuvant treatment in euthyroid ATA-positive women undergoing ICSI improved the outcome compared with those who did not take any medication. Since, there is only limited data on the efficacy of such treatment it should be accepted as experimental. It seems not necessary to administer these medications routinely in euthyroid ATA-positive women undergoing ICSI ${ }^{(5)}$.

\section{AIM OF THE WORK}

To investigate the impact of antithyroid antibodies on pregnancy outcome in cases of one or two failure of Intracytoplasmic Sperm Injection (ICSI) cycle.

\section{PATIENTS AND METHODS}

1. Study design: The present study is a prospective study. This study was conducted at Ahmed Oraby IVF center (private center), and was approved by the Medical Ethical Committee of AlAzhar University. Informed consent was obtained from every patient according to Hospital Ethics Committee. Age of patients, diseases status and previous treatments were recorded. 2. Sampling design: This study was done on 50 patients complaining of infertility with history of one or two failure of Intracytoplasmic Sperm Injection (ICSI) cycle. Patients divided into two groups, in the ATA positive group, 25 women were positive for TG-Ab and/or TPO-Ab, 25 women negative for TG-Ab and/or TPO-Ab served as controls. All patients did not receive any adjuvant treatment, such as glucocorticoids, anticoagulants, or other adjuvants. Patients with other autoimmune diseases, or positive for anticardiolipin antibody, antinuclear antibody, lupus anticoagulant, or rheumatoid factor were excluded from this study. Intracytoplasmic Sperm Injection (ICSI): Long term pituitary down-regulation performed in all patients with the following sequential regimen: 1All patients were treated with Triptorelin acetate (Decapeptyl $0.1 \mathrm{mg}$ ) therapy was initiated on the 21 st day of the preceding cycle and gonadotropins were added on day 2 of the cycle and E2 was measured after 15 days from agonist. 2Gonadotropin dosage was adjusted accordingly by patient age, basal hormonal profile, serum E2 levels, previous cycles, BMI and sonographic findings. Monitoring of ovulation at day 6 then 
every another day according to the ovarian response. 3- Human chorionic gonadotropin (choriomon $5000 \mathrm{IU}$ ) at a dose from 5.000 to $10000 \mathrm{IU}$ intramuscular (IM). When at least 2 follicles larger than $18 \mathrm{~mm}$ in diameter or more than 3 follicles larger than $17 \mathrm{~mm}$ in diameter, HCG (5,000-10,000 IU) was intramuscularly injected on the same day and oocytes were collected about 34-36 h later. The selection of fertilization program ICSI based on the semen condition on the day when the oocytes were collected. At 3-5 days after oocyte collection, embryos were transferred into the uterine; the number of transferred embryos varies according to patient age, embryo quality and previous ICSI trial outcome. Progesterone administered from the day of oocyte collection for luteal support. 14 days after embryo transfer, serum $\beta$-hCG measured. Once serum $\beta$-hCG examination showed positive, the patients received ultrasonography 2 weeks later to confirm the clinical pregnancy. Collection of clinical information: The clinical information including age, body mass index (BMI), duration of infertility, basal serum levels of follicle stimulating hormone $(\mathrm{bFSH})$ and luteinizing hormone $(\mathrm{bLH})$ collected. During the ICSI treatment, data including days of $\mathrm{Gn}$ treatment, total $\mathrm{Gn}$ dose, E2 level on the day of HCG, number of oocytes retrieved, fertilization rate, number of available embryos, number of embryo for transferring, pregnancy rate, implantation rate and abortion rate on going pregnancy rate recorded and analyzed. Detection of serum ATA: Serum ATA detected with the ARCHITECT Anti-TPO and ARCHITECT Anti-Tg kit. It's a Chemiluminescent Microparticle Immunoassay (CMIA) for the quantitative determination of the $\operatorname{IgG}$ class of thyroid peroxidase autoantibodies and thyroglobulin autoantibodies in human serum and plasma. Selection criteria: 1) Age between $18-39$ years old, 2) Body mass index (BMI) between 18 $25 \mathrm{~kg} / \mathrm{m}^{2}$, 3) Patients undergo ICSI treatment, 4) The second or more trial of ICSI, 5) Patients without other autoimmune diseases, or positive for anticardiolipin antibody, antinuclear antibody, lupus anticoagulant, or rheumatoid factor, 6) Patients did not receive any adjuvant treatment, such as glucocorticoids, anticoagulants, or other adjuvants. Exclusion criteria: 1) Females older than 39 years, 2) Obese patients, 3) First trial of ICSI, 4) Patients with other autoimmune diseases, or positive for anticardiolipin antibody, antinuclear antibody, lupus anticoagulant, or rheumatoid factor, 5) Patients receive any adjuvant treatment, such as glucocorticoids, anticoagulants, or other adjuvants. Statistical Analysis: The statistical analysis was performed using Microsoft Excel 2016, KY plot program version 2.0 beta, SPSS program version 15.0 for windows. The results are expressed as Mean, Standard, and Deviation for numerical values. $P$ values were calculated using the following tests: Rank sum (Mann Whitney) u test for unpaired comparison was used for the comparison between Group A (Antithyroid Antibodies Negative Cases), and Group B (Antithyroid Antibodies Positive Cases) numerical data variables. Chi-square test was comparison was used for the comparison between Group A (Antithyroid Antibodies Negative Cases), and Group B (Antithyroid Antibodies Positive Cases) nominal data variables. Significance difference was set at $\mathrm{P} \leq 0.05$.

\section{RESULTS}

Table (1): Patient demographic and clinical characteristics

\begin{tabular}{|c|c|c|c|}
\hline \multicolumn{2}{|c|}{ Characteristics } & $\begin{array}{c}\text { Group A } \\
\text { (Antithyroid } \\
\text { Antibodies } \\
\text { Negative Cases) }\end{array}$ & $\begin{array}{c}\text { Group B } \\
\text { (Antithyroid } \\
\text { Antibodies } \\
\text { Positive Cases) } \\
\end{array}$ \\
\hline \multicolumn{2}{|c|}{ No. of patients } & 25 & 25 \\
\hline \multicolumn{2}{|c|}{ Age (yrs.) } & $30.48 \pm 4.70$ & $28.48 \pm 4.79$ \\
\hline \multicolumn{2}{|c|}{$\begin{array}{l}\text { 1ry / 2ry } \\
\text { infertility }\end{array}$} & $20 / 5$ & $17 / 8$ \\
\hline \multirow{4}{*}{ שֶ } & $\begin{array}{l}\text { Male } \\
\text { factor }\end{array}$ & 12 & 11 \\
\hline & PCO & 5 & 3 \\
\hline & Tubal & 3 & 4 \\
\hline & $\begin{array}{l}\text { Un- } \\
\text { explore }\end{array}$ & 5 & 7 \\
\hline \multicolumn{2}{|c|}{ Duration } & $6.12 \pm 4.16$ & $6.12 \pm 2.94$ \\
\hline \multicolumn{2}{|c|}{ B Basal F.S.H. } & $6.42 \pm 1.36$ & $5.90 \pm 1.91$ \\
\hline \multicolumn{2}{|c|}{ B Basal L.H. } & $6.06 \pm 2.07$ & $6.17 \pm 2.03$ \\
\hline \multicolumn{2}{|l|}{ E2 } & $\begin{array}{c}1941.84 \pm \\
676.05\end{array}$ & $\begin{array}{c}1753.69 \pm \\
591.93\end{array}$ \\
\hline \multicolumn{2}{|c|}{ B.M.I. } & $22.26 \pm 1.55$ & $22.58 \pm 1.68$ \\
\hline
\end{tabular}

* Values are presented as the mean \pm standard deviation.

Comparison between group A (antithyroid antibodies negative cases) and group B (antithyroid antibodies positive cases) regarding clinical characteristics. 
Table (2): Summary of comparison

\begin{tabular}{|l|c|c|c|}
\hline \multirow{2}{*}{$\begin{array}{l}\text { Comparative } \\
\text { Variable }\end{array}$} & $\begin{array}{c}\text { P } \\
\text { value }\end{array}$ & Significance & \multirow{2}{*}{ Test } \\
\cline { 2 - 3 } Age & 0.24 & Not Significant & $\begin{array}{c}\text { Rank sum (mann } \\
\text { whitny) u test }\end{array}$ \\
\hline $\begin{array}{l}\text { Infertility } \\
\text { (1ry - 2ry) }\end{array}$ & 0.33 & Not Significant & Chi-square test \\
\hline Cause & 0.79 & Not Significant & Chi-square test \\
\hline Duration & 0.58 & Not Significant & $\begin{array}{c}\text { Rank sum (mann } \\
\text { whitny) u test }\end{array}$ \\
\hline $\begin{array}{l}\text { B Basal } \\
\text { F.S.H. }\end{array}$ & 0.387 & Not Significant & $\begin{array}{c}\text { Rank sum (mann } \\
\text { whitny) u test }\end{array}$ \\
\hline B Basal L.H. & 1.007 & Not Significant & $\begin{array}{c}\text { Rank sum (mann } \\
\text { whitny) u test }\end{array}$ \\
\hline E2. & 0.25 & Not Significant & $\begin{array}{c}\text { Rank sum (mann } \\
\text { whitny) u test }\end{array}$ \\
\hline B.M.I. & 0.4 & Not Significant & $\begin{array}{c}\text { Rank sum (mann } \\
\text { whitny) u test }\end{array}$ \\
\hline
\end{tabular}

Results of comparative variable.

Table (3): Differences between Group A (Antithyroid Antibodies Negative Cases), and Group B (Antithyroid Antibodies Positive Cases) in the number of ICSI trials, Days of stimulation, Total Gn Dose (75 IU/AMP.), Number of retrieved oocytes, Number of available Embryos, and Number of available Embryos Transferred.

\begin{tabular}{|c|c|c|c|c|c|}
\hline \multirow[b]{2}{*}{$\begin{array}{l}\text { Comparative } \\
\text { Variable }\end{array}$} & \multirow{2}{*}{\begin{tabular}{|c|} 
Group A \\
(Antithyroid \\
Antibodies \\
Negative \\
Cases)
\end{tabular}} & \multirow{2}{*}{\begin{tabular}{|c|} 
Group B \\
(Antithyroid \\
Antibodies \\
Positive \\
Cases)
\end{tabular}} & \multicolumn{2}{|r|}{ Result } & \multirow[b]{2}{*}{ Test } \\
\hline & & & $\begin{array}{c}\mathbf{P} \\
\text { value }\end{array}$ & Significance & \\
\hline $\begin{array}{l}\text { Number of } \\
\text { ICSI trials.: }\end{array}$ & $1.64 \pm 0.75$ & $1.4 \pm 0.57$ & 0.24 & $\begin{array}{c}\text { Not } \\
\text { Significant }\end{array}$ & \begin{tabular}{|c|} 
Rank \\
sum \\
(mann \\
whitny) \\
u test
\end{tabular} \\
\hline $\begin{array}{l}\text { Days of } \\
\text { stimulation }\end{array}$ & $11.96 \pm 1.39$ & $11.56 \pm 1.58$ & 0.41 & $\begin{array}{c}\text { Not } \\
\text { Significant }\end{array}$ & \begin{tabular}{|c|} 
Rank \\
sum \\
(mann \\
whitny) \\
u test
\end{tabular} \\
\hline $\begin{array}{l}\text { Total Gn } \\
\text { Dose (75 } \\
\text { IU/AMP.) }\end{array}$ & $25.76 \pm 6.70$ & $23.68 \pm 5.66$ & 0.28 & $\begin{array}{c}\text { Not } \\
\text { Significant }\end{array}$ & \begin{tabular}{|c|} 
Rank \\
sum \\
(mann \\
whitny) \\
u test
\end{tabular} \\
\hline $\begin{array}{l}\text { Number of } \\
\text { retrieved } \\
\text { oocytes }\end{array}$ & $9.52 \pm 2.94$ & $10.48 \pm 3.08$ & 0.24 & $\begin{array}{c}\text { Not } \\
\text { Significant }\end{array}$ & \begin{tabular}{|c|} 
Rank \\
sum \\
(mann \\
whitny) \\
u test
\end{tabular} \\
\hline $\begin{array}{l}\text { Number of } \\
\text { available } \\
\text { Embryos }\end{array}$ & $4.28 \pm 1.92$ & $5.04 \pm 2.20$ & 0.13 & $\begin{array}{c}\text { Not } \\
\text { Significant }\end{array}$ & \begin{tabular}{|l} 
Rank \\
sum \\
(mann \\
whitny) \\
u test
\end{tabular} \\
\hline $\begin{array}{l}\text { Number of } \\
\text { available } \\
\text { Embryos } \\
\text { Transferred }\end{array}$ & $1.84 \pm 0.74$ & $1.36 \pm 090$ & 0.07 & $\begin{array}{c}\text { Not } \\
\text { Significant }\end{array}$ & \begin{tabular}{|c|} 
Rank \\
sum \\
(mann \\
whitny) \\
u test
\end{tabular} \\
\hline
\end{tabular}

* Values are presented as the mean \pm standard deviation.
Table (4): Differences between Group A (Antithyroid Antibodies Negative Cases), and Group B (Antithyroid Antibodies Positive Cases) in the Drug of stimulation, Fertilization, Pregnancy, Implantation, and Abortion.

\begin{tabular}{|l|c|c|c|}
\hline \multicolumn{1}{|c|}{$\begin{array}{c}\text { Comparative } \\
\text { Variable }\end{array}$} & $\begin{array}{c}|c| \\
\text { Ralue }\end{array}$ & Significance & Test \\
\cline { 2 - 3 } $\begin{array}{l}\text { Drug of } \\
\text { stimulation }\end{array}$ & 0.77 & $\begin{array}{c}\text { Not } \\
\text { Significant }\end{array}$ & $\begin{array}{c}\text { Chi-square } \\
\text { test }\end{array}$ \\
\hline Fertilization & 0.39 & $\begin{array}{c}\text { Not } \\
\text { Significant }\end{array}$ & $\begin{array}{c}\text { Chi-square } \\
\text { test }\end{array}$ \\
\hline Pregnancy & 0.15 & $\begin{array}{c}\text { Not } \\
\text { Significant }\end{array}$ & $\begin{array}{c}\text { Chi-square } \\
\text { test }\end{array}$ \\
\hline Implantation & 0.14 & $\begin{array}{c}\text { Not } \\
\text { Significant }\end{array}$ & $\begin{array}{c}\text { Chi-square } \\
\text { test }\end{array}$ \\
\hline Abortion & 0.02 & Significant & $\begin{array}{c}\text { Chi-square } \\
\text { test }\end{array}$ \\
\hline
\end{tabular}

\section{DISCUSSION}

The presence of antithyroid antibodies (ATA) are frequently encountered in general population and approximately $1 / 5$ of childbearing age women are positive for the antithyroid peroxidase antibody (TPO-Ab) or antithyroglobulin antibody (TG-Ab) ${ }^{(1)}$. Autoimmune thyroid diseases are rather frequent in women in the childbearing age, affecting 5-20\% of them. They are characterized by the presence of antithyroglobulin and antithyroperoxidase antibodies, grouped under the definition of antithyroid antibodies (ATA). ATA are often detected in subjects complaining of hypo- or hyperthyroidism, but are no rarely found in patients without any sign of thyroid dysfunction ${ }^{(2)}$. Some evidence suggests that ATA could exert a negative influence on the female reproductive potential. Women with no signs of thyroid dysfunction who were ATA positive, the risk of spontaneous miscarriage increased three to five folds more than ATA negative women ${ }^{(3)}$. Some authors even reported an unexpectedly high ATA prevalence in euthyroid women with a history of three or more unsuccessful IVF cycles, and ATA-positivity was found to be associated with a low pregnancy rate in IVF ${ }^{(14)}$. On the contrary, other studies failed to detect any difference in IVF success rate between ATA positive and ATA negative women. Hypothyroidism in the early pregnancy may be associated with adverse outcomes such as miscarriage, pre-eclampsia, perinatal mortality and preterm birth ${ }^{(4)}$. Thyroid hormone receptors have 
been described in human oocyte and may assist in the stimulation of granulose cell function and trophoblastic differentiation. It has been suggested that antithyroid antibodies may be responsible for decreased fertility potential by blocking these receptors. Thus, the impact of these antibodies on the outcome of IVF cycles has been investigated. Although the presence of ATA was found to be related with poor IVF outcome in some studies ${ }^{(14)}$, others reported no effect ${ }^{(15)}$. The women did not take levotiroxine during the study. According to recent meta-analysis by Velkeniers et al., suchsupplementation could improve clinical pregnancy outcome in women with subclinical hypothyroidism and/or thyroid autoimmunity undergoing ART ${ }^{(16)}$. In all cases, the investigators used standard long ovulation induction protocol together with ICSI for fertilization (17). The significance level of alpha defined as 0.01 was chosen due to the large number of analyzed variables. In women undergoing IVF-ET, the relatively high incidence of autoantibodies in serum may be attributed to the poor IVF outcome ${ }^{(18)}$. Our study compared the results of ICSI in AntiTPO positive and Anti-TPO negative women. Data presented in the literature have consistently reported a reduction in implantation rate and an increase in early miscarriage rate in women with thyroid autoimmunity in comparison to negative controls ${ }^{(19)}$. Our seemingly contradictory results seem to confirm this hypothesis. While binding of anti-TPO antibodies to the surface of the egg can impede sperm's access during natural fertilization and classical IVF, it should not affect the quality of fertilization using ICSI which was used for all patients in our study. Our results are consistent with the results from (20) studies. The same conclusions were made by Zhong et al. who showed that the percentage of spontaneous abortions in a group of women positive for antiTPO was higher than in the control group (respectively, 26.9 and $11.8 \% p=0.002)^{(21)}$. A retrospectively study of a total of 114 patients positive for anti-thyroid peroxidase antibodies (Anti-TPO+ group) and 551 infertile women negative for anti-thyroid peroxidase antibodies (Anti-TPO- group) undergoing IVF with ICSI from April 2010 to April 2012 were analyzed retrospectively. There were no significant differences in age, BMI, basal FSH, LH, AMH levels and duration of infertility between the two main groups. No significant differences in terms of the days of ovarian stimulation, estradiol level in day 8 , total gonadotropin dose, number of oocytes retrieved, available embryos and blastocysts, number of embryos transferred nor in rates of fertilization, implantation, clinical pregnancy, live birth and abortion rate between two main groups were found. The study was revealed that patients with anti-TPO antibodies showed no significant differences in fertilization, implantation, pregnancy rates, live birth rates and no higher risk for miscarriage following ICSI-ET when compared with those negative for anti-thyroid antibodies ${ }^{(22)}$. A systematic literature review and meta-analysis were conducted to define the relation between Thyroid autoimmunity (TAI) per se and the outcome of in vitro fertilization (IVF)/intracytoplasmic sperm injection (ICSI) cycles. 12 studies were selected for the metaanalysis; a medline search was performed to identify all the comparative studies published from January 1990 to November 2015 in the English language literature on IVF/ICSI outcome in women with and without TAI. Six of the included studies were prospective cohort studies, and six were retrospective cohort studies. Results of search and description of studies revealed that thyroid autoimmunity (TAI) does not impact on IVF/ICSI outcome in terms of NOR and likelihood of fertilisation, implantation and clinical pregnancy. On the contrary, the presence of thyroid autoantibodies may have a detrimental effect on the course of a pregnancy, determining an increased risk of miscarriage and a decreased chance of live birth. ${ }^{(23)}$. However, given the possible modifying effects of age and serum TSH, further evidence is warranted prior to drawing inferences on causality. Further studies should be carried out in that field.

\section{CONCLUSION}

The present study show that patients with antiTPO antibodies showed no significant differences in fertilization, implantation, pregnancy rates, live birth rates but higher risk for miscarriage following intracytoplasmatic sperm injection- ICSI and embryo transfer when compared with those negative for antithyroid antibodies.

\section{CONFLICTS OF INTEREST}

There are no conflicts of interest. 


\section{REFERENCES}

1. McElduff A and Morris J (2008): Thyroid function tests and thyroid autoantibodies in an unselected population of women undergoing first trimester screening for aneuploidy. Aust N Z J Obstet Gynaecol., 48:478-80.

2. Poppe K, Velkeniers B, Glinoer D (2007): Thyroid disease and female reproduction. Clin Endocrinol., 66(3):309-321.

3. Poppe K, Velkeniers $B$ and Glinoer D (2008): The role of thyroid autoimmunity in infertility and pregnancy. Natl Clin Pract Endocrinol Metab., 4:394-405.

4. Negro R, Mangieri T, Coppola L, Presicce G, Casavola EC, Gismondi R, Locorotondo G, Caroli P, Pezzarossa A, Dazzi D and Hassan $H$ (2005): Levothyroxine treatment in thyroid peroxidase antibody-positive women undergoing assisted reproduction technologies: a prospective study. Hum Reprod., 20:1529-1533.

5. Revelli A, Casano S, Piane LD, Grassi G, Gennarelli G, Guidetti D, Massobrio M (2009): A retrospective study on IVF outcome in euthyroid patients with antithyroid antibodies: effects of levothyroxine, acetylsalicylic acid and prednisolon adjuvant treatments. Reprod. Biol. Endocrinol., 27, 137-145.

6. Debieve F, Duliere S, Bernard P (2009): To treat or not to treat euthyroid autoimmune disorder during pregnancy? Gynecol Obstet Invest., 67:178-82.

7. Poppe $K$ and Glinoer $D$ (2003): Thyroid autoimmunity and hypothyroidism before and during pregnancy. Hum Reprod Update, 9:149-61.

8. Van den Boogaard E, Vissenberg R, Land JA, van Wely M, van der Post JAM, Goddijn M, Bisschop PH (2011): Significance of (sub) clinical thyroid dysfunction and thyroid autoimmunity before conception and in early pregnancy: a systematic review. Human Reprod Update, 17(5):605-619.
9. Unuane D and Poppe K (2015): Female infertility: do we forget the thyroid? J Endocrinol Invest., 38(5):571-574.

10. Karacan M, Alwaeely F, Cebi Z, Berberoglugil M, Batukan M, Ulug M, Arvas A, Camlibel T (2013): Effect of antithyroid antibodies on ICSI outcome in antiphospholipid antibody-negative euthyroid women. Reprod Biomed Online, 27(4):376-380.

11. Mintziori G, Goulis DG, Gialamas E, Dosopoulos K, Zouzoulas D, Gitas G, Venetis CA, Toulis KA, Kolibianakis EM, Tarlatzis BC (2014): Association of TSH concentrations and thyroid autoimmunity with ivf outcome in women with tsh concentrations within normal adult range. Gynecol Obstet Invest., 77(2):84-88.

12. Toulis KA, Goulis DG, Venetis CA, Kolibianakis EM, Negro R, Tarlatzis BC, Papadimas I (2010): Risk of spontaneous miscarriage in euthyroid women with thyroid autoimmunity undergoing IVF: a meta-analysis. Eur J Endocrinol., 162(4):643-652.

13. Haller K, Sarapik A, Talja I, Salumets A, Uibo $R$ (2006): Controlled ovarian hyperstimulation changes the prevalence of serum autoantibodies in IVF. Am. J. Reprod. Immunol., 56: 364-370.

14. Kilic S, Tasdemir N, Yilmaz N, Yuksel B, Gul A and Batioglu S (2008): The effect of anti-thyroid antibodies on endometrial volume, embryo grade and IVF outcome. Gynecol Endocrinol., 24:649-655.

15. Negro R, Formoso G, Coppola L, Presicce G, Mangieri T, Pezzarossa A, Dazii D (2007): Euthyroid women with autoimmune disease undergoing assisted reproduction technologies: the role of autoimmunity and thyroid function. J. Endocrinol. Invest., 30, 3-8.

16. Velkeniers B, Van Meerhaeghe A, Poppe K, Unuane D, Tournaye H, Haentjens $P$ (2013): Levothyroxine treatment and pregnancy outcome in women with subclinical hypothyroidism undergoing assisted reproduction technologies: systematic review and meta-analysis of RCTs. Human Reprod Update, 19(3):251-258. 
17. Lukaszuk K, Liss J, Lukaszuk M, Maj B (2005): Optimization of estradiol supplementation during the luteal phase improves the pregnancy rate in women undergoing in vitro fertilization- embryo transfer cycles. Fertil Steril., 83(5):13721376.

18. Negro $R$ and Mestman JH (2011): Thyroid disease in pregnancy. Best Pract Res Clin Endocrinol Metab., 25(6):927-943.

19. Monteleone $P$, Parrini $D$, Faviana $P$, Carletti E, Casarosa E, Uccelli A, Cela V, Genazzani AR, Artini PG (2011): Female infertility related to thyroid autoimmunity: the ovarian follicle hypothesis. Am J Reprod Immunol., 66(2):108-114.

20. Tan S, Dieterle S, Pechlavanis S, Janssen OE, Fuhrer D (2014): Thyroid autoantibodies per se do not impair intracytoplasmic sperm injection outcome in euthyroid healthy women. Eur $\mathbf{J}$ Endocrinol., 170(4):495-500.
21. Zhong YP, Ying Y, Wu HT, Zhou XU, Wang YW, Li J, Shen XT, Li J (2012): Relationship between antithyroid antibody and pregnancy outcome following in vitro fertilization and embryo transfer. Int J Med Sci., 9(2):121-125.

22. Lukaszuk K, Kunicki M, Kulwikowska P, Liss J, Pastuszek E, Jaszczolt M, Meczekalski B, Skowronski K (2015): The impact of the presence of antithyroid antibodies on pregnancy outcome following intracytoplasmatic sperm injection-ICSI and embryo transfer in women with normal thyreotropine levels. J Endocrinol Invest., 38:1335-1343.

23. Busnelli A, Paffoni $A$, Fedele $L$ and Somigliana E (2016): The impact of thyroid autoimmunity on IVF/ICSI outcome: a systematic review and metaanalysis Human Reproduction Update, 22(6): 775-790. 